\title{
Evaluation of Evaporation Effect on the Film Thickness of Two Commercially Available Die Spacers on Three Different Surfaces
}

\author{
Dinesh Kumar ${ }^{1}$, Amit Khattak², Ranjoy Hazara ${ }^{3}$, Ayush Srivastav ${ }^{4}$
}

\begin{abstract}
The present study was done to evaluate the effect of evaporation on the film thickness of two commercially available die spacers on three different surfaces. Die spacers used were Nice Fit and Durolan. Both die spacers were applied on three different surfaces-glass slide, die stone slab without hardener, and die stone slab with hardener after the bottles were left open for $0,2,4,8$, and 12 hours. The film thickness was measured with the help of SEM. Nice Fit die spacer showed an increase of 53, 139.5, 159.6, and 190.9\% and Durolan showed an increase in 45.3, $142.6,181.9$, and $200 \%$ for $2,4,8$, and 12 hours, respectively. Therefore, the number of coats must be reduced to achieve an ideal die spacer film thickness in the range of $25-40 \mu \mathrm{m}$. The thickness of die spacer on die stone slab without hardener was more compared to that on glass slide and on die stone slab coated with a hardener.

Keywords: Die spacer, Epoxy resin, Evaporation, Film thickness, SEM.

International Journal of Experimental Dental Science (2020): 10.5005/jp-journals-10029-1211
\end{abstract}

\section{INTRODUCTION}

Success of a cast restoration is dependent on a number of factors. A proper fit of the casting on to the prepared tooth and its cementation is an important aspect that determines its long-term clinical success. Casting fit is a function of many variables, related to changes in size and shape, introduced by the materials used in fabrication of a restoration. Even if all the variables are controlled carefully to ensure a perfect fit, the restoration still will not fit because of insufficient space for a luting agent.

The main requirement of a full-cast crown is that it should seat completely on the prepared tooth without ant hydraulic pressure from the luting agent. Failure to completely seat the crown will result in supraocclusion, loss of proximal contact, food impaction, plaque retention, secondary caries, and periodontal breakdown.

The most popular and accurate method ${ }^{1-3}$ to achieve adequate internal relief in full veneer cast restoration is the application of die spacer. Die spacer is a solution that is painted on to the die before fabrication of a wax pattern. The use of die spacer provides uniform space for the luting agent, reduces elevation of the cast restorations, improves outflow of excess cement, and lowers seating forces. Ideal thickness for luting cement ranges from 25 to $40 \mu \mathrm{m}$, which is provided by application of die spacer. Die spacer thickness should be large enough to allow proper seating of the casting yet not so large as to cause excessive cement thickness.

Basic composition of a die spacer includes an organic solvent like ketone with fine metal oxide particles dispersed in the medium. The metal oxide powder must remain dispersed in the organic solvent; any change in the volume of solvent due to evaporation will lead to thickening of the die spacer. This will result in alteration of the film thickness of the die spacer.

The evaporation of organic matrix liquid is unavoidable when the bottle stands open for some time while the die spacer is being applied on a die. An open bottle will probably result in higher concentration of metal oxide particles in die spacer solution resulting in an increased spacer thickness for each coating.
${ }^{1}$ Department of Prosthodontics, Army Dental Centre R \& R, New Delhi, India

${ }^{2}$ Department of Prosthodontics and Crown and Bridge, Army Dental Centre R \& R, New Delhi, India

${ }^{3,4}$ Department of Army Dental Centre R \& R, New Delhi, India

Corresponding Author: Dinesh Kumar, Department of Prosthodontics, Army Dental Centre R \& R, New Delhi, India, Phone: +91 8806661685, e-mail: drdineshsaini@yahoo.co.in

How to cite this article: Kumar D, Khattak A, Hazara R, et al. Evaluation of Evaporation Effect on the Film Thickness of Two Commercially Available Die Spacers on Three Different Surfaces. Int J Experiment Dent Sci 2020;9(2):47-51.

Source of support: Nil

Conflict of interest: None

The clinical consequence of larger die spacer thickness resulting from open bottle and evaporation of the organic matrix may be excess luting cement film thickness. In order to provide ideal cement film thickness, it is mandatory that thickness of die spacer should be controlled to $25-40 \mu \mathrm{m}$.

Grajower and Zuberi ${ }^{4}$ (1989) found $140 \%$ increase in film thickness of an old Tru Fit die spacer. Gegauff and Rosenstiel ${ }^{5}$ (1989) found $148 \%$ increase in film thickness in old vs. new Tru Fit bottles.

The present study was undertaken:

- To evaluate the effect of evaporation of die spacer components on die spacer thickness.

- To compare the die spacer thickness on a glass slide, on a die stone slab without hardener, and on a die stone slab coated with a hardener.

- To evaluate the percentage increase in die spacer film thickness after the bottle is left open for a progressively increasing time interval. 
- To ascertain the number of applications of die spacer that are required to achieve an optimal film thickness, after the bottle is left open for incremental time intervals.

\section{Materials and Methods}

This in vitro study was undertaken to evaluate the effect of evaporation of die spacer components on die spacer film thickness. In this study, two die spacers Nice Fit (Shofu Inc., Japan) and Durolan (DFS, Germany) commonly available in the market were used. Both the die spacers were applied on three surfaces: (1) glass slide, (2) die stone slab without hardener, (3) die stone slab coated with die hardener after the die spacer bottles were left open for 0, 2, 4, 8, and 12 hours. The film thickness for each application of die spacer was measured with the help of SEM.

\section{Methods}

The study was carried out in following steps:

- Fabrication of glass and die stone slabs

- Application of die spacer

- Designation of test samples

- Coating with epoxy resin

- Preparation of samples for SEM study

- Measurement of thickness of die spacer under SEM

- Analysis of results

\section{Fabrication of Glass and Die Stone Slabs}

Three surfaces used for application of die spacer were fabricated as follows:

Fabrication of glass slide: The 2-mm-thick standard-size rectangular glass slides were cut into a dimension of $6 \mathrm{~cm} \times 8 \mathrm{~mm}$. Total 30 glass slides of above dimensions were prepared: 15 slides for application of Nice Fit and 15 slides for application of Durolan.

\section{Fabrication of slab of die stone:}

- Total $33 \mathrm{~g}$ of powder and $8 \mathrm{~mL}$ of water were vacuum mixed according to the manufacturer's instructions.

- Base plate wax was used for beading of a conventional dental glass slab to provide $2 \mathrm{~mm}$ thickness of dental stone. This beaded glass slab was placed on the vibrator and the die stone was poured onto the slab.

- The die stone slab was cut with the help of a sharp BP blade after initial set but before final set to obtain rectangular samples of $6 \mathrm{~cm} \times 8 \mathrm{~mm} \times 2 \mathrm{~mm}$.

- After final set of the die stone, the slabs of die stone were finished at the margins with 100 grit fine sand paper. A total of 60 die stone slabs of the size $6 \mathrm{~cm} \times 8 \mathrm{~mm} \times 2 \mathrm{~mm}$ were fabricated. The surface of the stone slab that was in contact with the glass slab was used for application of die spacer. A total of 60 such die stone slabs were fabricated.

Application of die hardener: Out of 60 die stone slabs, 30 were coated with cyanoacrylate die hardener. Two drops of cyanoacrylate resins were placed at one end of the slab and air was blown to spread the hardener evenly on the slab surface.

\section{Application of Die Spacer}

Application of Nice Fit die spacer: A silver Nice Fit spacer bottle was left open for $0,2,4,8$, and 12 hours at $22^{\circ} \mathrm{C}$. After each time interval, the bottle was closed for the handshaking mixing process, according to the manufacturer's recommendations.

After mixing, a single layer of die spacer was applied to clean glass slide, with a single, even brush stroke. A number 5 sable brush was used. One brush was used for 10 applications. Similarly, die spacer was applied to die stone slab and to the die stone slab with hardener.

For each interval of time, die spacer was applied on three glass slides, three die stone slabs without hardener, and on three die stone slabs with hardener. From one application, three readings for film thickness were measured at $L 2, L 3$, and $L 4$ sites making a total sample of nine readings for each time interval as shown below.

\begin{tabular}{|c|c|c|c|c|c|}
\hline & L1 & L2 & L3 & L4 & L5 \\
\hline \multirow[t]{2}{*}{$8 \mathrm{~cm}$} & & & & & \\
\hline & & $6 \mathrm{cr}$ & & & \\
\hline
\end{tabular}

The entire procedure was repeated for the application of Durolan Die spacer.

\section{Designation of Test Samples}

Following the procedure outlined above, a total of 30 glass slides, 30 die stone slabs, and 30 die stone slabs with hardener were obtained. Half of these slides were coated with Nice Fit $(X)$ and half of them were coated with Durolan $(\mathrm{Y})$ die spacer.

The die spacer bottle was left open for a progressively, incremental length of time. Nine samples were coated during each interval and were grouped as follows:

Group I: Time interval 0 hour

Group II: Time interval 2 hours

Group III: Time interval 4 hours

Group IV: Time interval 8 hours

Group V: Time interval 12 hours

Each of these groups I, II, III, IV, V were further subdivided into following subgroups:

Subgroup A: Die spacer applied on glass slide

Subgroup B: Die spacer applied on die stone slab without hardener Subgroup C: Die spacer applied on die stone slab with hardener

The samples were dried and stored at $22^{\circ} \mathrm{C}$.

\section{Coating with Epoxy Resin}

A thin layer of epoxy resin was coated on the sample, to hold the film of die spacer in place, while sectioning the samples for the SEM study. This was achieved by mixing epoxy resin base and catalyst according to the manufacturer's instructions and by pouring on each sample of glass and die stone. Samples were left undisturbed for 9 hours for the complete setting of epoxy resin.

\section{Preparation of the Samples for SEM Study}

Each samples were cut cross-sectionally at the marking L1, L2, L3, L4, and L5 locations using precision cutting saw with diamond blade. The film thickness was measured at L2, L3, and L4 locations. Each sample was polished with 320-600 grit silicone carbide paper Tri-M-Ite (3 $\mathrm{m}$ dental product) and washed with water.

\section{Measurement of Thickness of Die Spacer Under SEM}

Each sample was mounted vertically on the SEM mounting block using silver adhesive (Sigma silver conductive paint and adhesive) and film thickness was measured at $150 \times$ magnification. The mean 
Evaporation Effect on the Film Thickness of Two Commercially Available Die Spacers

Table 1: Percentage increase in thickness vs time for Nice Fit $(X)$ die spacer compared to thickness at 0 hour

\begin{tabular}{|c|c|c|c|c|c|}
\hline \multicolumn{6}{|c|}{ Subgroup $A$} \\
\hline Time intervals (hours) & 0 & 2 & 4 & 8 & 12 \\
\hline Film thickness $(\mu \mathrm{m})$ & 8.1000 & 12.4000 & 19.4000 & 21.0333 & 23.5667 \\
\hline Percentage increase & $0 \%$ & $53 \%$ & $139.5 \%$ & $159.6 \%$ & $190.9 \%$ \\
\hline \multicolumn{6}{|c|}{ Subgroup $B$} \\
\hline Time intervals (hours) & 0 & 2 & 4 & 8 & 12 \\
\hline Film thickness $(\mu \mathrm{m})$ & 8.4000 & 12.6667 & 20.1333 & 21.7667 & 24.4667 \\
\hline Percentage increase & $0 \%$ & $51 \%$ & $139.6 \%$ & $159.1 \%$ & $191.2 \%$ \\
\hline \multicolumn{6}{|c|}{ Subgroup C } \\
\hline Time intervals (hours) & 0 & 2 & 4 & 8 & 12 \\
\hline Film thickness $(\mu \mathrm{m})$ & 8.0667 & 12.4667 & 19.4667 & 21.0667 & 23.5667 \\
\hline Percentage increase & $0 \%$ & $54.5 \%$ & $141.3 \%$ & $161.1 \%$ & $192.1 \%$ \\
\hline
\end{tabular}

Table 2: Percentage increase in thickness vs time for Durolan $(Y)$ die spacer compared to thickness at 0 hour

\begin{tabular}{|c|c|c|c|c|c|}
\hline \multicolumn{6}{|c|}{ Subgroup A } \\
\hline Time intervals (hours) & 0 & 2 & 4 & 8 & 12 \\
\hline Film thickness $(\mu \mathrm{m})$ & 13.6667 & 19.8667 & 33.1667 & 38.5333 & 41.0333 \\
\hline Percentage increase & $0 \%$ & $45.3 \%$ & $142.6 \%$ & $181.9 \%$ & $200 \%$ \\
\hline \multicolumn{6}{|c|}{ Subgroup $B$} \\
\hline Time Intervals (hour) & 0 & 2 & 4 & 8 & 12 \\
\hline Film thickness $(\mu \mathrm{m})$ & 13.7000 & 20.2000 & 33.8667 & 39.2667 & 43.0333 \\
\hline Percentage increase & $0 \%$ & $47.4 \%$ & $147.2 \%$ & $186.6 \%$ & $214 \%$ \\
\hline \multicolumn{6}{|c|}{ Subgroup C } \\
\hline Time intervals (hours) & 0 & 2 & 4 & 8 & 12 \\
\hline Film thickness $(\mu \mathrm{m})$ & 13.4333 & 19.7667 & 33.5000 & 38.5667 & 41.8000 \\
\hline Percentage increase & $0 \%$ & $47.1 \%$ & $149.3 \%$ & $187 \%$ & $211.1 \%$ \\
\hline
\end{tabular}

of five readings from one site was taken to get the film thickness per sample.

\section{Analysis of Results}

The die spacer thickness was measured for each sample and the results were subjected to the statistical analysis using the two-way and one-way analysis of variance. Further Student " $t$-" test was applied to find out the significance of variation between groups and subgroups.

\section{Results}

Table 1 shows percentage increase in film thickness for all the three subgroups for various time intervals for Nice Fit die spacer. Table 2 shows percentage thickness for Durolan die spacer for different intervals of time. The one-way analysis of variance for film thickness measurement for different slides and for different intervals of time was found statistically significant $(p<0.05)$ for both the die spacers.

To compare film thickness of die spacer on three different types of slide, a Student " $t$-" test was performed for Nice Fit and Durolan. Comparison between film thickness on glass slide (subgroup A) and die stone slab coated with hardener (subgroup $C$ ) was not statistically significant $(p>0.05)$ but comparison of thickness of subgroup $B$ with subgroups $A$ and $C$ was statistically significant (Table 3).
Table 3: Comparison of Nice Fit die spacer thickness between different types of slides for particular time

\begin{tabular}{ll}
\hline Comparison between & Significance \\
\hline$A: B$ & $\mathrm{~S}$ \\
$A: C$ & $\mathrm{~N}$ \\
$B: C$ & $\mathrm{~S}$ \\
\hline
\end{tabular}

S: significant $p$ value $<0.05$

$\mathrm{N}$ : not significant $p$ value $>0.05$

\section{Discussion}

An optimal space of $25-40 \mu \mathrm{m}$ should exist between the internal surface of the casting and the prepared surface of the tooth everywhere except a small area immediately adjacent to the margins. ${ }^{3}$ The space provides room for the luting agent and allows complete seating of the restoration during cementation.

Conversely, if the cement space is too wide, the casting will be loose on the tooth, resistance form will be reduced, and the position of the casting will be difficult to maintain during evaluation and occlusal adjustment. In addition, the risk of the crown loosening during function increases considerably, and its longevity is adversely affected. ${ }^{3}$

Die spacer is a solution that is painted on the die before the fabrication of the pattern. The die spacer consists of metal oxide powders and adhesives dispensed in an organic liquid such as 
ketone. Painting of the layers of die spacer on the die provides space for the cement, helps in easy seating of the crown, reduces the hydraulic pressure, and helps to reduce the force applied to seat a crown. ${ }^{6,7}$

For optimal results, die spacer thickness should be uniform ranging from 25 to $40 \mu \mathrm{m}$. The amount of space required between a prepared tooth and casting can be controlled by varying the number of coats of die spacer. To maintain optimal clinical effectiveness of the die spacer, its composition must be held constant because change in composition will lead to a change in the film thickness of the die spacer. If the bottle is open, the organic matrix liquid tends to evaporate because of its high vapor pressure, thereby changing the die spacer composition. The overall time that a bottle is open during clinical use can affect the die spacer thickness and therefore long-term clinical success of a restoration.

Most traditional die spacers are somewhat similar in composition; they comprise of metal oxide, adhesives, and a volatile organic matrix liquid. Differences in the evaporation rates and the effects of evaporation, if any, are expected with die spacers from different manufacturers. Therefore, two die spacers from different manufacturers, i.e., Nice Fit (Shofu Inc, Kyoto, Japan) and Durolan (DFS, Riedenburg, Germany) were selected to enhance the direct clinical significance of the present study to rule out the variations occurring in only one material.

In the present study, three different surfaces were used for die spacer application: (1) glass slide, (2) die stone slab without hardener, and (3) die stone slab with hardener. Glass slide being a nonabsorbable smooth surface was used in this study to confirm the thickness of a single uniform stroke of application of die spacer. Two other surfaces, viz., die stone slabs with and without hardener, were used to mimic the clinical practice of fabrication of dies. The effect of die hardener on the film thickness of a single application of die spacer was also evaluated.

According to a study by Oliva et al., ${ }^{2}$ measurement of the film thickness varied significantly when measured at seven locations on the 100 dies. The cusp tips and occlusoaxial line angles had the least thickness of the die spacer when compared to other locations on the die. To eliminate the variable of different film thicknesses at different location on a die, flat, smooth, and uniform surface with little or no intersample surface variation was required. Therefore, die stone slabs of the size $6 \mathrm{~cm} \times 8 \mathrm{~mm} \times 2 \mathrm{~mm}$ were fabricated by vacuum mixing die stone. The surface of the die stone slab, which had set in contact with the glass slab, was absolutely flat, smooth, and uniform and, therefore, was used for the application of die spacer.

Thus, variables due to surface roughness of stone dies and variables due to different film thickness at different locations on a prepared tooth die were eliminated and selection of glass microscopic slide and die stone slab for application of die spacer was deemed appropriate.

To maintain uniformity of application, the die spacer was applied between the L1 and L5 marks on each slide because thickness may vary from the point of initial contact of brush to the point of removal of brush. The film thickness was measured at three points $(L 2, L 3, L 4)$ at a uniform distance from each other to avoid variations among samples.

The difference in samples of die stone without hardener (subgroup B) could be attributed to the porous nature of the die stone, absorbing more of organic matrix and due to the wetting properties of die spacer liquid on the nonporous smooth surface compared to the porous surface of die stone. The film thickness of die stone with hardener was almost similar to glass slide; this may have been achieved by blocking of die stone pores with die hardener providing a smooth nonporous surface.

The increase in film thickness of die spacer with open bottle time probably is caused by the subsequent higher concentration of metal oxide particles in the die spacer solution with more metal oxide being applied per brush stroke. The higher concentration of adhesive during evaporation also may contribute to increased thickness.

Another study be Psillakis et al. ${ }^{8}$ showed increase in die spacer thickness by $1,142,105$, and $329 \%$ when the bottles were left open for 1, 4, 8, and 24 hours, respectively, compared with bottle open for 0 hour. The results of the present study were similar to the above findings.

As it is evident from Table 1 that the increase in film thickness of Nice Fit die spacer occurs as the time interval increases. This can help us in determining of number of coats that can be curtailed to achieve an ideal die spacer film thickness in the range of $25-40 \mu \mathrm{m}$. After an interval of 2 hours, Nice Fit die spacer coat should be reduced from four coats at 0 hour to three coats. After 4 hours interval, the coat should be reduced to two to achieve ideal film thickness. But after 8 hours, single uniform coat of die spacer gave a film thickness of $21 \mu \mathrm{m}$, which is not sufficient, and two coats of die spacer will give film thickness of more than $40 \mu \mathrm{m}$, leading to excessive relief under casting. Therefore, thinner has to be added to achieve the ideal range of die spacer film thickness but a study is needed to ascertain the amount of thinner that needs to be added.

Similarly, single coat of Durolan die spacer (Table 2) gives $13 \mu \mathrm{m}$ of average film thickness to achieve ideal thickness of 25-40 $\mu \mathrm{m}$, three coats must be applied at 0 hour. At 2 hours interval of time, the film thickness of die spacer increased to 20 $\mu \mathrm{m}$ approximately, so the number of coats must be reduced to two. At 4 hours interval of time, the film thickness of die spacer increased to $33 \mu \mathrm{m}$, so single coat is sufficient. But after 8 hours, excess relief may be provided due to increased thickness of the single coat of die spacer, so thinner has to be added to achieve the ideal range of die spacer film thickness.

\section{Summary and Conclusion}

The present study was undertaken to evaluate the effect of evaporation on die spacer thickness of the two commercially available die spacer materials. Thickness of the die spacer was evaluated on the glass slides, on die stone slabs without hardener, and on die stone slabs coated with hardener. The bottles of Nice fit and Durolan die spacers were left open for $0,2,4,8$, and 12 hours at $22^{\circ} \mathrm{C}$. One uniform brush stroke of spacer was applied to clean glass slides, die stone slabs, and die stone slabs coated with hardener, for each interval of time. The thickness of die spacer was measured and subjected to the statistical analysis.

Study showed that:

- Average film thickness for single uniform coat of die spacer was $8.1 \mu \mathrm{m}$ for Nice Fit and $13.4 \mu \mathrm{m}$ for Durolan die spacer on glass slide.

- The die spacer thickness increased with open bottle time for both the die spacers tested. 
- Increase in film thickness of both the die spacers was more or less comparable to each other for all the time intervals.

- Thickness of die spacer applied on the die stone slab without hardener was more as compared to that on the glass slide and on the die stone slab coated with hardener.

- The thickness of the die spacer on the glass slide and die stone slab coated with hardener was found to be almost similar because coating of die hardener produced smooth and nonabsorbable surface.

- As the thickness of die spacer increases with time, the number of coats applied to the die should be reduced to achieve ideal film thickness of 25-40 $\mu \mathrm{m}$. Therefore, for Nice Fit die spacer four coats are required from fresh bottle, three coats when a bottle is left open for 2 hours, and two coats when bottle is left open for 4 hours. Similarly, for Durolan three coats are needed at 0 hour, two coats after 2 hour, and one coat after 4 hours interval of time. After 8 hours, a single coat of die spacer would result in a film thickness beyond the ideal range. Hence, thinner liquid supplied by the manufacturer would have to be added to reduce the thickness. However, further studies are required to ascertain the amount of thinner, which is required to be added and the effect this would have on the thickness of the die spacer.

\section{References}

1. Campagni WV, Wright W, Martinoff JT. Effect of die spacer on the seating of complete cast gold crowns with grooves. J Prosthet Dent 1986;55(3):324-328. DOI: 10.1016/0022-3913(86)90112-5.

2. Hager TS, Gardner FM, Edge MJ. The effect of selective die spacer placement techniques on the seatability of castings. J Prosthet Dent 1993;2(1):56-60. DOI: 10.1111/j.1532-849X.1993.tb00382.x.

3. Dixon DL, Breeding LC, Lilly KR. Use of luting agents with an implant system: Part II. J Prosthet Dent 1992;68(4):885-889. DOI: 10.1016/00223913(92)90544-K.

4. Grajower R, Zuberi, Lewinstein I. Improving the fit of crowns with die spacers. J Prosthet Dent 1989;61(5):555-563. DOI: 10.1016/00223913(89)90275-8.

5. Gegauff AG, Rosenstiel SF. Reassessment of die-spacer with dynamic loading during cementation. J Prosthet Dent 1989;61(6):655-658. DOI: 10.1016/S0022-3913(89)80036-8.

6. Oliva RA, Lowe JA, Ozaki MM. Film thickness measurements of a paint-on die spacer. J Prosthet Dent 1988;60(2):180-184. DOI: 10.1016/0022-3913(88)90312-5.

7. Psillakis JJ, Mc Alarney ME, Wright RF, et al. Effect of evaporation and mixing technique on die spacer thickness. J Prosthet Dent 2001;85(1):82-87. DOI: 10.1067/mpr.2001.113028.

8. Psillakis J, Mc Alarney M, Wright R, et al. Effect of evaporation and mixing technique on die spacer thickness: a preliminary study. J Prosthet Dent 2002;87(2):132-138. DOI: 10.1016/S0022-3913(02)70088-7. 